\title{
Modifikasi Perencanaan Dermaga General Cargo dengan Kapasitas Kapal 10.000 DWT di Kabupaten Sampang, Madura
}

\author{
Daniar R.P.H., Chomaedhi, R. Buyung A., Indratmo D. \\ Departemen Teknik Infrastruktur Sipil Fakultas Vokasi ITS \\ Email: rissandy.daniar.pratama.17310@gmail.com
}

\begin{abstract}
Design modifications of General Cargo jetty is located in Sampang district, Madura. This General Cargo jetty is expected to increase the stopping point of the ship which is contain a lot of oil drilling area, as the gate of economy in Madura and Eastern Indonesia. Design modification of this jetty is to observe the General Cargo which will be planned on sampang so that it can accomodate the ship with a capacity of up to 10,000 DWT.

In this planning, there are two structures that are counted, the first is trestle structure as a bridge connecting the dock and the mainland, the second is jetty itself as the driving force of all loading and unloading activities of dry bulk goods. The bottom structure is planned to use steel pipe pile starting from $914 \mathrm{~mm}$ diameter 14mm thickness in trestle up to $1016 \mathrm{~mm}$ thickness $16 \mathrm{~mm}$ and $19 \mathrm{~mm}$ at dock pole. For concrete structures, used concrete quality $f^{\prime} c=35 \mathrm{MPa}$ for dock plate and mooring Dolphin, beam, pilecap and shear ring using $f^{\prime} \mathrm{c}=40 \mathrm{MPa}$

From the results of design modification obtained dock dimension along the $160 \mathrm{~m}$ and width of $32 \mathrm{~m}$ plus lenght of Trestle $588 \mathrm{~m}$. height of plate $35 \mathrm{~cm}$ and $50 \mathrm{~cm}$, for horizontal and vertical beam is $1000 \times 1300 \mathrm{~mm}, 300 \times 500 \mathrm{~mm}$ side beams, $400 \times 600 \mathrm{~mm}$ secondary beams and a listplank block $500 \times 3000$, dimensions of pilecap with single pile is $2500 \mathrm{~m} \times 2500 \times 2100$. To meet the requirements of pons shear. The dock uses a mobile crane tool for loading and unloading and uses a trailer truck with 45T capacity.
\end{abstract}

Keywords: Jetty, General Cargo, 10.000 DWT, Trestle.

\begin{abstract}
Abstrak
Modifikasi desain dermaga General Cargo berada di kabupaten Sampang, Madura. Dermaga General Cargo ini diharapkan dapat menambah wilayah pemberhentian kapal yang juga banyak area pengeboran minyak, selaku pintu gerbang perekonomian di Madura dan Kawasan Timur Indonesia. Modifikasi perencanaan dermaga ini meninjau dermaga General Cargo yang akan direncanakan di sampang sehingga dapat melayani kapal dengan kapasitas sampai 10.000 DWT.

Dalam perencanaan ini terdapat 2 struktur yang di hitung diantaranya pertama strutur trestle sebagai jembatan penghubung dermaga dan daratan, yang kedua dermaga itu sendiri sebagai penggerak segala kegiatan bongkar muat barang barang curah kering atau general cargo. Struktur bawah direncanakan menggunakan pondasi tiang pancang baja (steel pipe pile) mulai diameter $914 \mathrm{~mm}$ tebal $19 \mathrm{~mm}$ di trestle dan $1500 \mathrm{~mm}$ tebal $22 \mathrm{~mm}$ pada tiang dermaga. Untuk struktur yang menggunakan beton, dipakai beton mutu f'c $=35$ MPa seperti plat dermaga dan mooring dolphin, balok, pilecap dan shear ring menggunakan mutu f'c $=40 \mathrm{MPa}$

Dari hasil modifikasi desain dermaga General Cargo diperoleh dimensi dermaga sepanjang 160m dan lebar 32m ditambah panajng Trestle $588 \mathrm{~m}$. Dimensi pelat tinggi $35 \mathrm{~cm}$ dan $50 \mathrm{~cm}$, untuk balok diantaranya memanjang dan melintang $1000 \times 1300 \mathrm{~mm}$, balok tepi 300x500mm , balok anak $400 \mathrm{x}$ $600 \mathrm{~mm}$ kemudian ada balok listplank $500 \times 3000$ dimensi pilecap dengan satu pancang $2500 \mathrm{~m} \times 2500$ x 2100 agar memenuhi persyaratan geser pons. Dermaga menggunakan alat mobile crane untuk bongkar muat dan menggunakan truk trailer dengan kapasitan $45 \mathrm{~T}$
\end{abstract}

Kata kunci: Dermaga, General Cargo, 10.000 DWT, Trestle

Media Informasi \& Komunikasi Aplikasi Teknik Sipil Terkini 


\section{Pendahuluan}

Dengan semakin besarnya pertumbuhan ekonomi di wilayah Jawa Timur termasuk pulau Madura, maka semakin besar pula kebutuhan akan pelabuhan - pelabuhan bongkar muat ekspor - impor di daerah Sampang, Sumenep dan sekitar Pulau Madura. Untuk membantu pengembangan wilayah Madura yang banyak pengeboran minyak, pelabuhan ini juga bisa untuk tempat penyimpanan atau pengiriman alat - alat untuk pengeboran.

Dalam perencanaan ini akan direncanakan pengembangan pelabuhan Curah Basah atau Pelabuhan Minyak akan dikembangkan dermaga barang atau General Cargo. General Cargo yaitu barang yang dikirim dalam bentuk satuan seperti mobil, truk, mesin, serta barang yang dibungkus dalam peti, karung, drum, dan lain sebagainya.

Agar dapat terwujudnya kelancaran dan kenyamanan dalam perekonomian maka perencanaan dermaga, wilayah camplong, Kabupaten Pamekasan Madura dengan menggunakan tipe dermaga jenis General Cargo.

\section{Metodologi}

Langkah-langkah yang dilakukan dalam studi ini adalah sebagai berikut:

1. Mengumpulkan data teknik yang diperlukan seperti data tanah, data batchymetri, dan gambar struktur, data angin, data gelombang.

2. Menentukan spesifikasi kapal.

3. Merencanakan spesifikasi dan ukuran dermaga.
4. Menganalisis perencanaan struktur, seperti: perencanaan dimensi, beban yang terjadi, perencanaan fender, perencanaan boulder.

5. Mengontrol permodelan yang meliputi periode, gaya gempa dasar,

6. Menganalisis gaya dalam dan melakukan perhitungan kebutuhan tulangan kemudian menyajikan hasil perhitungan tersebut dalam bentuk gambar perencanaan.

\section{Hasil dan Pembahasan}

Perencanaan dalam studi ini dilakukan dengan memasukkan data-data perencanaan kedalam alat bantu untuk dijadikan permodelan.

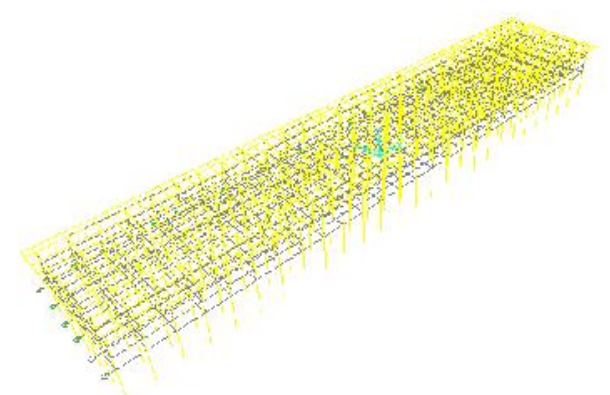

Gambar 1. Permodelan struktur

Permodelan tersebut dikontrol hingga memenuhi persyaratan sehingga analisis gaya dalamnya dapat digunakan untuk perhitungan kebutuhan tulangan. Hasil dari studi ini adalah sebagai berikut:

1. Gaya gempa dasar

Beban gempa yang bekerja pada struktur dermaga dihitung secara dinamis dengan menggunakan respon spektrum menurut SNI 2833-2013. 
Faktor Situs dan Parameter Gempa Lainnya

a. PGA (Percepatan puncak batuan dasar) : 0.25

b. Ss (Parameter respon spectra percepatan gempa untuk periode pendek $\mathrm{T}=0.2$ detik : 0.2

c. S1 (Parameter respon spectra percepatan gempa untuk periode 1 detik : 0.2

d. $\mathrm{F}_{\mathrm{a}}$ (Faktor amplikasi periode pendek) : 1.7 (Tabel 3 SNI 28332013)

e. FPGA (Faktor amplikasi getaran terkait percepatan pada getaran periode nol detik) : 1.7 (Tabel 3 SNI 2833-2013)

f. $\mathrm{F}_{\mathrm{v}}$ (Faktor amplikasi untuk periode 1 detik) : 3.2 (Tabel 4 SNI 2833-2013)

g. S SS (Nilai spectra permukaan tanah pada periode pendek 0.2 detik): $\mathrm{S}_{\mathrm{DS}} \quad=\mathrm{F}_{\mathrm{a}} \times \mathrm{S}_{\mathrm{S}}=$ $1.7 \times 0.4=0.68$

h. $\mathrm{S}_{\mathrm{D} 1}$ (Nilai spectra permukaan tanah pada periode pendek 1 detik): $\mathrm{S}_{\mathrm{D} 1} \quad=\mathrm{F}_{\mathrm{v}} \times \mathrm{S}_{1}=$ $3.2 \times 0.2=0.35$

i. $\mathrm{As}=\mathrm{F}_{\mathrm{PGA}} \times \mathrm{PGA}=1.7 \times 0.25=$ 0.425

j. I (Importance Factor) : 1 (Standard design criteria for port in Indonesia 1984, Tabel 5.5)

k. R (Faktor modifikasi respon) : 4 (pasal 5.9.3.2. SNI 2833-2013)

1. Scale Factor : $\mathrm{I} / \mathrm{R} \times \mathrm{g}=1 / 4 \times 9.8=$ 2.45

$\mathrm{Ts}=\mathrm{S}_{\mathrm{D} 1} / \mathrm{S}_{\mathrm{DS}}=0.35 / 0.68=0.94$ $\mathrm{T}_{0}=0.2 \times \mathrm{Ts}=0.2 \times 0.94=0.19$
Untuk $\mathrm{T}<\mathrm{T}_{0}$, spectrum respon percepatan desain:

$\mathrm{C}_{\mathrm{SM}}=\left(\mathrm{S}_{\mathrm{DS}}-\mathrm{A}_{\mathrm{S}}\right) \mathrm{T} / \mathrm{T}_{0}+\mathrm{A}_{\mathrm{S}}=0.425$

Untuk $\mathrm{T} \geq \mathrm{T}_{0}$ dan $<\mathrm{Ts}$, spectrum respon percepatan desain : $\mathrm{C}_{\mathrm{SM}}=\mathrm{S}_{\mathrm{DS}}$

Untuk $\mathrm{T}>\mathrm{Ts}$, spectrum respon percepatan desain :

$\mathrm{C}_{\mathrm{SM}}=\mathrm{S}_{\mathrm{D} 1} / \mathrm{T}$

Tabel 1 menyajikan respon spektrum untuk gempa wilayah 3 dengan tipe tanah lunak.

Tabel 1: Respon spektrum untuk gempa wilayah 3 dengan type tanah lunak

\begin{tabular}{ccc}
\hline $\mathrm{T}$ & $\begin{array}{c}\mathrm{T} \\
\text { (detik) }\end{array}$ & $\begin{array}{c}\mathrm{C}_{\mathrm{SM}} \\
(\mathrm{g})\end{array}$ \\
\hline 0 & 0 & 0.425 \\
$\mathrm{~T}_{0}$ & 0.19 & 0.680 \\
$\mathrm{~T}_{\mathrm{s}}$ & 0.94 & 0.680 \\
$\mathrm{~T}_{\mathrm{s}}+0.1$ & 1.04 & 0.615 \\
$\mathrm{~T}_{\mathrm{s}}+0.1$ & 1.14 & 0.561 \\
$\mathrm{~T}_{\mathrm{s}}+0.1$ & 2.24 & 0.516 \\
$\mathrm{~T}_{\mathrm{s}}+0.1$ & 1.34 & 0.477 \\
$\mathrm{~T}_{\mathrm{s}}+0.1$ & 1.44 & 0.444 \\
$\mathrm{~T}_{\mathrm{s}}+0.1$ & 1.54 & 0.415 \\
$\mathrm{~T}_{\mathrm{s}}+0.1$ & 1.64 & 0.390 \\
$\mathrm{~T}_{\mathrm{s}}+0.1$ & 1.74 & 0.368 \\
$\mathrm{~T}_{\mathrm{s}}+0.1$ & 1.84 & 0.348 \\
$\mathrm{~T}_{\mathrm{s}}+0.1$ & 1.94 & 0.330 \\
$\mathrm{~T}_{\mathrm{s}}+0.1$ & 2.04 & 0.314 \\
$\mathrm{~T}_{\mathrm{s}}+0.1$ & 2.14 & 0.299 \\
$\mathrm{~T}_{\mathrm{s}}+0.1$ & 2.24 & 0.286 \\
$\mathrm{~T}_{\mathrm{s}}+0.1$ & 2.34 & 0.273 \\
$\mathrm{~T}_{\mathrm{s}}+0.1$ & 2.44 & 0.262 \\
$\mathrm{~T}_{\mathrm{s}}+0.1$ & 2.54 & 0.252 \\
$\mathrm{~T}_{\mathrm{s}}+0.1$ & 2.64 & 0.242 \\
$\mathrm{~T}_{\mathrm{s}}+0.1$ & 2.74 & 0.233 \\
$\mathrm{~T}_{\mathrm{s}}+0.1$ & 2.84 & 0.225 \\
$\mathrm{~T}_{\mathrm{s}}+0.1$ & 2.94 & 0.218 \\
$\mathrm{~T}_{\mathrm{s}}+0.1$ & 3.04 & 0.210 \\
$\mathrm{~T}_{\mathrm{s}}+0.1$ & 3.14 & 0.204 \\
\hline
\end{tabular}

2. Perhitungan tulangan

Perhitungan tulangan struktur menggunakan hasil output dari SAP. 
Hasil output SAP sebagai berikut:

$$
\begin{array}{ll}
\mathrm{Mu}_{\text {Lap }} & =-1936933522 \mathrm{~N}-\mathrm{mm} \\
\mathrm{Mu}_{\text {Lap }} & =2156963262 \mathrm{~N}-\mathrm{mm} \\
\mathrm{Mu}_{\text {Tum }} & =-4920201463 \mathrm{~N}-\mathrm{mm} \\
\mathrm{Mu}_{\text {Tum }} & =2739014076 \mathrm{~N}-\mathrm{mm} \\
\mathrm{T} & =800558824 \mathrm{~N}-\mathrm{mm} \\
\mathrm{V}_{\text {Lap }} & =1305220,7 \mathrm{~N} \\
\mathrm{~V}_{\text {Tum }} & =-1745173 \mathrm{~N}
\end{array}
$$

Untuk perumusan balok:

Tulangan lentur

$$
\begin{aligned}
& M n=M u / \varphi \ldots \ldots . \\
& M=f y / 0,85 . f c^{\prime} \\
& R n=M n / b \cdot d^{2} \ldots .
\end{aligned}
$$

Rasio tulangan minnimum :

$$
\begin{aligned}
& \text { Pmin }=1.4 / \mathrm{fy} \\
& \rho \max =\frac{0,85 \beta 1 \cdot f c \mid}{f y} \cdot\left(\frac{600}{600+\gamma \nu}\right) \ldots . \\
& \rho b=0,75 . \rho \max \\
& \text { Ast }=\rho . b . d
\end{aligned}
$$

Cek kemampuan nominal :

$\mathrm{T}=$ Ast . fy.

$\mathrm{a}=\mathrm{T} /(0,85 . \mathrm{fc} \cdot \mathrm{b})$

$\varphi \mathrm{Mn}=\varphi \cdot \mathrm{T}(\mathrm{d}-\mathrm{a} / 2)$

Tulangan torsi

$$
\mathrm{Vu} \leq_{\varphi} \mathrm{Vc}
$$

Tidak perlu tulangan geser

$$
0,5_{\varphi} . \mathrm{Vc}<\mathrm{Vu} \leq{ }_{\varphi} . \mathrm{Vc}
$$

Tulangan geser minimum

$\varphi . \mathrm{Vc}<\mathrm{Vu} \leq{ }_{\varphi}(\mathrm{Vc}+\mathrm{Vs} \min )[2-64]$

Tulangan geser minimum

Vs $\min =\frac{1 . b w, d}{3}$

$\varphi .(\mathrm{Vc}+\mathrm{Vs} \min )<\mathrm{Vu} \leq_{\varphi} .(\mathrm{Vc}+$ $\frac{1}{3} \sqrt{\left(f c^{\prime} \cdot b v \cdot d\right)}$.

Perlu tulangan geser

Vs $\min =\frac{1, b w, d}{3}$

$\varphi .\left(\mathrm{Vc}+\frac{1}{3} \sqrt{\left(f c^{\prime} \cdot b w \cdot d\right)}<\mathrm{Vu} \leq_{\varphi} .(\mathrm{Vc}\right.$

$+\frac{2}{3} \sqrt{\left.f c^{\prime} \cdot b w \cdot d\right)}$

Perlu tulangan geser

Vs $\min =\frac{1 . b w, d}{3}$

$$
\mathrm{Vs}>\frac{2}{3} \sqrt{\left.f c^{\prime} \cdot b w \cdot d\right)}
$$

Tulangan pelat lantai dan pile cap

$$
\begin{aligned}
& \mathrm{Mn}=\mathrm{Mu} / \varphi \ldots \ldots \\
& \mathrm{m}=\mathrm{fy} / 0,85 . \mathrm{fc} \\
& \mathrm{Rn}=\mathrm{Mn} / \mathrm{b} \cdot \mathrm{d}^{2} \ldots \ldots
\end{aligned}
$$

Rasio tulangan minimum :

$$
\begin{aligned}
& \rho \min =1.4 / \mathrm{fy} \ldots \ldots \ldots \ldots \ldots \ldots \ldots \\
& \rho \max =\frac{0,05 . \rho 1 \cdot f e t}{f y} \cdot\left(\frac{600}{600+f y}\right)
\end{aligned}
$$

\begin{tabular}{|c|c|c|}
\hline $\mathrm{Ha}$ & $=$ & $\begin{array}{l}\text { kapasitas daya dukung } \\
\text { horisontal tiang }\end{array}$ \\
\hline $\mathrm{E}$ & $=$ & modulus elastisitas bahan \\
\hline $\mathrm{I}$ & $=$ & momen inersia penampang \\
\hline$\delta$ & $=$ & $\begin{array}{l}\text { pergeseran } \\
(\text { diambil } 1 \mathrm{~cm})\end{array}$ \\
\hline & $=$ & $\begin{array}{l}\text { koefisien reaksi } \\
\text { dasar }\end{array}$ \\
\hline & $=$ & ko. $^{-0,5} \ldots .$. \\
\hline ko & $=$ & 0,2 Eo. $D^{-3 / 4}$ \\
\hline & & $\begin{array}{c}\text { (nilai k apabila pergeseran } \\
\text { diambil } \quad \text { sebesar } 1 \mathrm{~cm} \text { ) } \\
\ldots \ldots \ldots \ldots \ldots \ldots \ldots \ldots \ldots \ldots \ldots \ldots \\
\ldots\end{array}$ \\
\hline
\end{tabular}

$$
\rho b=0,75 . \rho \max
$$

Cek kemampuan nominal :

$$
\begin{aligned}
& \mathrm{T}=\text { Ast } . \text { fy } \ldots \ldots \ldots \ldots \ldots \ldots . .[2-42] \\
& \mathrm{a}=\mathrm{T} /(0,85 . \mathrm{fc} \cdot . \mathrm{b}) \ldots \ldots . . .[2-43] \\
& \varphi \mathrm{Mn}=\varphi . \mathrm{T}(\mathrm{d}-\mathrm{a} / 2) \ldots \ldots \ldots . .[2-44]
\end{aligned}
$$

3. Analisis daya dukung tanah

Daya dukung horisontal dihitung berdasarkan beban pergeseran normal yang terjadi pada kepala tiang, yaitu pergeseran paling maksimum pada ujung tiang. Bila besarnya pergeseran normal sudah ditetapkan, maka daya dukung mendatar yang diijinkan dapat ditentukan berdasarkan Sosrodarsono 2000, dengan persamaan berikut ini :

$$
H a=\frac{4 E I \cdot \beta^{s}}{1+\beta h} \cdot \delta_{L}
$$

Dengan : 


\begin{tabular}{|c|c|c|}
\hline $\mathrm{y}$ & $=$ & $\begin{array}{l}\text { besarnya pergeseran yang } \\
\text { dicari }\end{array}$ \\
\hline Eo & $=$ & modulus elastisitas tanah \\
\hline & $=$ & $\ldots \ldots \ldots \ldots \ldots \ldots \ldots(2.51)$ \\
\hline $\mathrm{h}$ & $=$ & $\begin{array}{l}\text { tinggi tiang yang menonjol } \\
\text { di atas permukaan tanah. }\end{array}$ \\
\hline$\beta$ & $=$ & $\sqrt[\frac{1}{4}]{\frac{k \cdot D}{4 E I}}$. \\
\hline
\end{tabular}

\section{Simpulan}

Dari modifikasi desain struktur dermaga General Cargo, dapat disimpulkan sebagai berikut:

1. Dengan bobot kapal rencana 10.000 DWT, ditetapkan dimensi dermaga dengan panjang $160 \mathrm{~m}$, lebar 31.5 $\mathrm{m}$, tinggi apron $+3.00 \mathrm{mLWS}$ dan kedalaman air rencana $-9.5 \mathrm{mLWS}$

2. Panjang Trestle $588 \mathrm{~m}$ dengan lebar $11 \mathrm{~m}$.

3. Dimensi plat dermaga (plat beton) ditetapkan menggunakan ketebalan 35 dan $50 \mathrm{~cm}$. Plat di lintasan trestle $35 \mathrm{~cm}$.

\section{Daftar Pustaka}

Badan Standarisasi Nasional, 2012. Tata Cara Perencanaan Ketahanan Gempa Untuk Struktur Gedung Dan Non Gedung (SNI 1726 : 2012)

Badan Standarisasi Nasional, 2002. Tata Cara perhitungan Struktur Beton Untuk Bangunan Gedung (SK SNI 03-2847-2002). Jakarta : Standard Design Criteria for Port in Indonesia, 1984. Maritime Development Programme Directorate General of Sea Commonications, Jakarta Departemen Pekerjaan Umum, 1971

Peraturan Beton Bertulang Indonesia. Direktorat Penye- lidikan Masalah Bangunan Gedung

Setiawan, Agus. 2008. Perencanaan Struktur Baja Dengan Metode LFRD. Jakarta: Erlangga.

Sosrodarsono, S., Nakazawa, K. 2000. Mekanika Tanah dan Teknik Pondasi. Jakarta: PT Pradnya Paramita

Technical Standards For Port and Harbour Facilities in Japan, Beureau of Ports and Harbours, Ministry of Transport. 
